\title{
Computer and internet use among people with long-standing spinal cord injury: a cross-sectional survey in the Netherlands
}

\author{
Marcel W. M. Post ${ }^{1,2} \cdot$ Jacqueline M. P. Leenders ${ }^{3} \cdot$ Marga Tepper $^{2} \cdot$ Govert J. Snoek $^{4} \cdot$ \\ ALLRISC • Luc H. V. van der Woude ${ }^{5}$. Jacinthe J. E. Adriaansen ${ }^{1}$
}

Received: 8 January 2018 / Revised: 14 December 2018 / Accepted: 15 December 2018 / Published online: 28 January 2019

(c) International Spinal Cord Society 2019

\begin{abstract}
Study design: Cross-sectional survey

Objectives: To describe computer and Internet use (other than for work or study) among people with long-standing spinal cord injury (SCI), examine associations between demographic and lesion characteristics and Internet use, and examine associations between Internet use and mental health, participation, and life satisfaction.

Setting: Community, The Netherlands

Methods: Participants were 265 individuals living with SCI for at least 10 years, who were 18-35 at the onset of SCI, aged 28-65 at the time of the study and wheelchair-user. Scales for General and Health-related Internet use were developed.

Results: Nearly all (97.7\%) participants had Internet access and $98.4 \%$ of those used it daily or weekly. Of those with tetraplegia, $47.4 \%$ had assistive devices for computer use. General Internet use, such as following news and online banking, was very frequent. Websites with information on general health or accessibility were typically visited a few times a year. Three-quarters never visited websites of other individuals with SCI or foreign websites with information on SCI. General Internet use was associated with male gender, younger age, and higher education. Participants with tetraplegia scored higher on Health-related Internet use compared to participants with paraplegia. Health-related Internet use was associated with worse participation, but not with the other psychosocial variables.

Conclusion: Internet has become part of daily life of people with SCI in the Netherlands. However, only one association between Internet use and indicators of psychosocial functioning was found. Possible underuse of adaptive devices and of SCI-specific websites warrant further investigation.
\end{abstract}

\section{Introduction}

In the last decades, the utilization of computers, smartphones, and the Internet has created tremendous opportunities for people with physical disabilities. Shopping, studying, obtaining health information, maintaining social and professional relationships, the Internet allows even individuals with severely restricted mobility to circumvent transportation and accessibility barriers [1-5]. It is, therefore, not surprising that people with disabilities spend more hours a day on the Internet compared to people with paid work $[6,7]$.

However, large surveys among people with spinal cord injury (SCI) in the United States between 2003 and 2006 showed only two-thirds of participants to have Internet access at home and of those who had Internet access, only $68.6 \%$ used the Internet daily [8,9]. Of those with tetraplegia and a computer, only $35 \%$ used an assistive 
device to enable computer and Internet use, such as voice activation or recognition, modified mouse, typing splint, or head pointer $[8,9]$.

Further, little information is available on what people with SCI use the Internet for. A study in Turkey reported that the major use of the Internet seemed to be social integration and social support [6]. In an American survey, participants with SCI who had Internet access used it for email (90.7\%), shopping (66.0\%), visiting disability and health websites $(61.3 \%)$, employment $(38.4 \%)$, and chat rooms $(15.5 \%)$ [9].

Studies on the possible benefits of Internet use among people with SCI are sparse and reported diverging results. The only intervention study reported no effects on healthrelated quality of life [10]. One very large cross-sectional study $(N=4618)$ showed more depressed mood among non-users as compared to daily Internet users, but without differences between daily users and those who used the Internet on a weekly or monthly basis [11]. Other studies found that occasional Internet users had better scores on a variety of health-related quality of life outcomes compared to non-users [8], but negative associations between frequent Internet use and health and occupation scores were also reported, such as a negative influence of frequent online gaming on mental health [8, 12].

In short, literature on Internet access and use is sparse, partly outdated, shows Internet use to be far from universal and is inconclusive with respect to its possible benefits. Against this background the objectives of this study were the following: (1) to describe computer and Internet use in people with long-standing (>10 years) SCI in the Netherlands, (2) to explore associations between demographic and lesion characteristics and Internet use, and (3) to examine associations between Internet use and measures of mental health, participation and life satisfaction.

\section{Methods}

\section{Study design}

Cross-sectional survey.

\section{Participants}

Data used in this study were collected as part of the ALLRISC research program [13, 14]. Inclusion criteria were: living with SCI for at least 10 years, between 18 and 35 years of age at the time of onset of the SCI, between 28 and 65 years of age at the time of inclusion in the study, and using a wheelchair, at least for longer distances $(>500 \mathrm{~m})$. Individuals with insufficient mastery of the Dutch language to respond to an oral interview or to understand test instructions were excluded. Data were collected between November 2011 and February 2014.

\section{Procedure}

Potential participants were identified from the medical files of all eight rehabilitation centers with a speciality in SCI rehabilitation in the Netherlands. Sampling was stratified according to TSI, with strata 10-20 years, 20-30 years and more than 30 years post-injury. If the number of potential participants allowed, random samples per stratum were drawn. Potential participants received an invitation letter from their rehabilitation physician and informed consent was obtained from all participants. Participation in the study included completing a mailed questionnaire and a visit to the rehabilitation center for a medical assessment, oral interview and physical tests.

\section{Instruments}

Internet use was measured with items adapted from a questionnaire used by Statistics Netherlands with additional study-specific items [15]. A 0-4 point response scale was used (not at all, few times a year, monthly, weekly, daily). We constructed two scales. First items were categorized as either general or health-related based on their contents. After that, items in each category were subjected to explorative factor analysis (orthogonal rotation, default SPSS settings) to explore the possible usefulness of further subdivision of these scales, but this was not the case. Finally, reliability analysis was used to remove items with low corrected item-total correlations $(<0.30)$.

The final scale for General Internet use consisted of ten items, such as reading news, online banking, online shopping and visiting social network sites. Two other general items (e-mail and searching second-hand goods) were omitted because of low inter-item correlations. The total score is the average score of the items, with a range of 0 (no general Internet use) up to 4 (daily use for all items). Internal consistency of this scale was satisfactory, with a Cronbach's alpha of 0.77 and corrected item-total correlations ranging from 0.36 to 0.57 .

The scale for Health-related Internet use consisted also of 10 items, such as looking for information about SCI, about assistive devices, visiting the website of the Dutch SCI association and international SCI-related websites. The total score also ranges from 0 up to 4 . Internal consistency of this scale was good, with Cronbach's alpha of 0.86 and corrected item-total correlations ranging from 0.44 to 0.66 .

The item on the frequency of online gaming was separately analyzed. The response categories of this item were 
dichotomized into 1 (daily or weekly) or 0 (less than weekly) because of low numbers of participants in the nouse and higher-use categories.

Demographic variables included: age at the time of the study, sex, relationship status (single versus married or stable relationship), level of education (low: up to high school, versus high: college, university), and employment status (no paid work versus having paid work for $1 \mathrm{~h} /$ week or more).

SCI characteristics were assessed according to the International Standards for Neurological Classification of SCI [16]. American Spinal Injury Association Injury Severity (AIS) grades A and B were categorized as motor complete lesions and AIS grades $\mathrm{C}$ and D as motor incomplete lesions.

Mental health was measured with the Mental Health scale of the Medical Outcome Study 36-item Short-Form (SF-36) [17]. This scale measures mood during the past 4 weeks with a total score between 0 (low mood) and 100. The MHI-5 showed validity in a cohort of people with SCI [18].

Life satisfaction was measured with five items on satisfaction with overall QoL and with health, daily activities, relationships, and living conditions from the short-form of the World Health Organization Quality of Life (WHOQOLBREF) [19]. The total score ranges between 5 (low life satisfaction) and 25 . This scale is valid for use in people with SCI [20].

Participation in productive, leisure and social activities was measured with the Utrecht Scale for Evaluation of Rehabilitation-Participation (USER-P) [21]. Two of the three subscales were used: restrictions measuring the degree to which participants need help or have difficulty performing certain activities, such as paid work, housework, leisure activities and contacts with friends (11 items) and satisfaction, measuring the degree participants are satisfied with respect to the same activities (10 items). Total scores of both scales range between 0 (worst participation) and 100 (best participation). The USER-P is a valid measure for use in people with SCI [22].

\section{Statistics}

Descriptive and non-parametric statistics (Chi-square; Mann-Whitney and Kruskall-Wallis tests, Spearman Correlations and Somer's $D$, where appropriate) were used to analyze Internet use and associations with demographic and SCI characteristics, and with psychosocial outcomes. If bivariable associations were significant, linear regression analysis was performed to examine whether correlation coefficients significant in bivariate analyses would remain significant after adjustment for demographic and SCI characteristics. No violations of assumptions of linear regression were found.
Table 1 Characteristics of the study sample $(N=265)$

\begin{tabular}{ll}
\hline Age (years; Md (IQR)) & $47.9 ;(41.8-55)$ \\
$\%<45$ years & 41.9 \\
$\%$ 46-60 years & 47.9 \\
$\%>60$ years & 10.2 \\
TSI (years; Md (IQR)) & $22 ;(17-31)$ \\
$\%$ 10-19 years & 37 \\
$\%$ 20-29 years & 34.3 \\
$\% \geq 30$ years & 28.7 \\
Gender (\% male) & 73.2 \\
Traumatic spinal cord injury (\%) & 90.6 \\
Tetraplegia (\%) & 40.5 \\
Motor complete lesion (\%) & 81.5 \\
Married or in stable relationship (\%) & 60.8 \\
High education (\%) & 56.9 \\
Employment (\% having paid work) & 49.8 \\
\hline
\end{tabular}

TSI time since injury, IQR inter quartile range

${ }^{\mathrm{a}} N=258$

\section{Results}

A total of 282 individuals with SCI participated in the ALLRISC study, of whom 265 (94\%) completed the selfreport questionnaire and were included in the current analysis. Their characteristics are displayed in Table 1.

\section{Internet access and assistive devices}

A total of 259 (97.7\%) participants indicated to have Internet access. Of those with Internet access, $72.5 \%$ used a desktop computer to access the Internet, $59.6 \%$ a laptop, $35.1 \%$ a tablet and $37.7 \%$ a smartphone (more than one option possible). No significant differences between participants with paraplegia and tetraplegia were found. Of those having a computer, $27.8 \%$ had assistive devices for computer use, $47.4 \%$ of those with tetraplegia and $9.9 \%$ of those with paraplegia $(p<0.001)$. The most often used adaptive devices by participants with tetraplegia were a trackball $(29.5 \%)$, a typing aid (20\%), an adapted keyboard (11.4\%), and speech-recognition software (11.4\%). A few participants with paraplegia used an adapted touch screen, a document holder and/or an adapted mouse.

\section{Internet use and associated factors}

Almost all (92.3\%) participants who had a computer used it daily, $6.2 \%$ weekly, and $1.5 \%$ less than once a week. Type and frequency of use of the Internet is detailed in Table 2. Using search engines (95.7\%), sending/receiving e-mail (93.8\%), following news (72.9\%), and online banking 
Table 2 Use of the Internet other than for work or study $(N=259)$

\begin{tabular}{|c|c|c|c|c|c|}
\hline Goal of Internet use & Daily & Weekly & Monthly & Few times a year & Not at all \\
\hline${ }^{\mathrm{a}}$ Search engines & 71 & 24.7 & 3.1 & 0 & 1.2 \\
\hline${ }^{\mathrm{a}}$ News & 53.1 & 19.8 & 6.2 & 4.7 & 16.3 \\
\hline Email & 85.3 & 8.5 & 1.5 & 1.5 & 3.1 \\
\hline a'One-to-one contact (e.g., Skype, chat) & 18.7 & 16 & 8.9 & 11.7 & 44.7 \\
\hline${ }^{\mathrm{a} B a n k i n g}$ & 16.6 & 56 & 16.2 & 1.9 & 9.3 \\
\hline${ }^{a}$ Organizing travel, vacation & 2.7 & 1.9 & 5.8 & 53.9 & 35.7 \\
\hline${ }^{\mathrm{a}}$ Looking for goods and prices & 6.9 & 24.3 & 30.9 & 24.7 & 13.1 \\
\hline${ }^{\mathrm{a}}$ Online shopping & 3.5 & 10.4 & 34.0 & 38.2 & 13.9 \\
\hline Searching second-hand goods sites & 6.9 & 12.7 & 19.7 & 33.2 & 72.6 \\
\hline${ }^{\text {a}}$ Social network sites & 36 & 15.5 & 7.8 & 3.1 & 37.6 \\
\hline${ }^{a}$ Discussion groups, panels, etc. & 5.8 & 8.1 & 11.2 & 16.7 & 58.1 \\
\hline a'Download music, video & 8.9 & 16.2 & 11.6 & 21.6 & 41.7 \\
\hline Gaming & 11.2 & 7.8 & 2.7 & 5.0 & 73.7 \\
\hline${ }^{\mathrm{b}}$ Info about spinal cord injury (SCI) & 0.8 & 3.9 & 10.9 & 58.1 & 26.4 \\
\hline${ }^{\mathrm{b}}$ Info about health in general & 1.2 & 3.1 & 19.4 & 57 & 19.4 \\
\hline${ }^{\mathrm{b}}$ Info about assistive devices & 1.6 & 2.3 & 14.7 & 60.1 & 21.3 \\
\hline${ }^{\mathrm{b}}$ Info about accessibility buildings etc. & 1.5 & 6.2 & 16.6 & 51 & 24.7 \\
\hline${ }^{\mathrm{b}}$ Consultation with health professionals & 1.2 & 0.8 & 4.3 & 23.6 & 70.2 \\
\hline${ }^{\mathrm{b}}$ Websites Dutch rehab centers & 0.4 & 0 & 1.6 & 30.2 & 67.8 \\
\hline${ }^{b}$ Website Dutch SCI association & 0.8 & 0.4 & 5 & 40.7 & 47.3 \\
\hline${ }^{\mathrm{b}}$ Website Spinalnet & 0.8 & 0.4 & 5 & 28.2 & 65.6 \\
\hline${ }^{\mathrm{b}}$ Websites of other people with SCI & 1.2 & 0.8 & 2.7 & 21.2 & 74.1 \\
\hline${ }^{\mathrm{b}}$ International SCI websites & 0.4 & 1.2 & 1.2 & 20.9 & 76.4 \\
\hline
\end{tabular}

Item included in the General Internet use scale

${ }^{\mathrm{b}}$ Item included in the Health-related Internet use scale
(72.6\%) were by far the most often mentioned types of daily or weekly use. About half of all participants with Internet access visited social network sites such as Facebook daily or weekly, but about one-thirds of participants did not use these at all.

Websites with information on general health or accessibility were typically visited a few times a year (Table 2). Websites with information on SCI were visited less often. About $40 \%$ indicated to never visit the website of the Dutch association of SCI patients (www.dwarslaesie.nl), and three-quarters never visited websites of other individuals with SCI or foreign websites with information on SCI.

The median score on the scale for General Internet use was 1.9 (IQR 1.4-2.4) and this score showed a more or less normal distribution (Kolmogorov-Smirnov test, $p=0.099$ ). Daily or weekly online gaming was reported by $18.5 \%$ of participants with Internet access and about three-quarters indicated to never play online games. General Internet use was higher among men, younger participants and those with higher education, compared to women, older participants and those with lower levels of education and with tetraplegia.
The score on the scale for Health-related Internet use was strongly skewed, with a median score of .6 (IQR 0.4-0.9; K-S test $p<0.001$ ) on a 0-4 scale. Differences in Healthrelated Internet use were only seen for level of SCI, participants with tetraplegia scoring on average higher compared to participants with paraplegia (Table 3).

General Internet use was moderately strong associated with Health-related Internet use (Spearman correlation 0.43, $p<0.001)$. The frequency of online gaming was weakly (correlation 0.24, $p<0.001$ ) associated with General, but not with Health-related Internet use (correlation 0.09, $p=$ 0.136).

\section{Associations between Internet use and psychosocial variables}

One significant correlation was found between the frequency of Internet use and measures of psychosocial functioning of participants, a correlation of $-0.17(p=$ 0.008 ) between more Health-related Internet use and worse levels of experienced participation. This correlation remained significant after adjustment for age, level of SCI, 
level of education and time since onset of SCI (beta -0.12 , $p=0.045)$ (Table 4).

\section{Discussion}

This study showed very high levels of Internet access and use in a cross-sectional sample of Dutch people with longstanding SCI around 2012-2013. Nearly half of those with tetraplegia used one or more assistive devices for computer use. Participants used the Internet more often for general

Table 3 Associations between demographic and SCI characteristics and Internet use

\begin{tabular}{|c|c|c|c|}
\hline & $\begin{array}{l}\text { General } \\
\text { Internet use } \\
\text { Median } \\
\text { (IQR) }\end{array}$ & $\begin{array}{l}\text { Health-related } \\
\text { Internet use } \\
\text { Median (IQR) }\end{array}$ & $\begin{array}{l}\text { Online gaming } \\
\text { (\% daily or } \\
\text { weekly) }\end{array}$ \\
\hline \multicolumn{4}{|l|}{ Gender } \\
\hline Male & $2(1)$ & $0.6(.6)$ & 15.3 \\
\hline Female & $1.7(1.1)^{* *}$ & $0.6(.5)$ & $26.8^{*}$ \\
\hline \multicolumn{4}{|l|}{ Age } \\
\hline$<45$ years & $2.2(.8)$ & $0.7(.6)$ & 25 \\
\hline $45-60$ years & $1.8(1.1)$ & $0.6(.5)$ & 14.1 \\
\hline$>60$ years & $1.5(1.2)^{* * *}$ & $0.5(.7)$ & $11.1 ; p=0.054$ \\
\hline \multicolumn{4}{|c|}{ Level of education } \\
\hline Low & $1.8(1.1)$ & $0.5(.5)$ & 22.3 \\
\hline High & $2(.9)^{* *}$ & $0.6(.5)^{*}$ & 17.6 \\
\hline \multicolumn{4}{|l|}{ Level of lesion } \\
\hline Tetraplegia & $2.1(1)$ & $0.7(.7)$ & 16.7 \\
\hline Paraplegia & $1.9(1)^{*}$ & $0.5(.5)^{*}$ & 19.6 \\
\hline \multicolumn{4}{|l|}{$\begin{array}{l}\text { Completeness of } \\
\text { lesion }\end{array}$} \\
\hline Incomplete & $1.9(1)$ & $0.6(.5)$ & 18.8 \\
\hline Complete & $2.1(1.1)$ & $0.6(.6)$ & 18.4 \\
\hline \multicolumn{4}{|l|}{ Time since onset } \\
\hline 10-20 years & $2.1(.8)$ & $0.7(.6)$ & 23.3 \\
\hline $21-30$ years & $1.9(.9)$ & $0.6(.5)$ & 14.3 \\
\hline$>30$ years & $1.6(1.1)^{* * *}$ & $0.5(.4)^{*}$ & 14.9 \\
\hline
\end{tabular}

Table 4 Associations between Internet use and psychosocial functioning purposes compared to health-related purposes. SCI-related websites were visited a few times a year or not at all, and about three-quarters never visited websites of other people with SCI or international websites with information about SCI.

Internet and assistive devices use were much higher in this study than reported in previous American surveys [4, 8, 9]. Those surveys, however, were performed more than 10 years ago and Internet use will also have increased in Americans with SCI since then. Recent figures from this and other countries are unfortunately lacking.

To put the figures on Internet use into perspective, we compared our figures to those of the general Dutch population aged 12-75 over the year 2012 [15]. The $97.7 \%$ of participants having Internet access and $92.3 \%$ daily users is somewhat higher than the $92.8 \%$ with Internet access and $78.2 \%$ daily users in the Dutch general population, respectively. In our study, $88.8 \%$ used the Internet at least monthly for online banking, against $73.3 \%$ within the last three months in the Dutch population. For following the news, this was $79.1 \%$ and $50.1 \%$, respectively. However, only $10 \%$ of our participants used the Internet for organizing travel or vacation and $23.7 \%$ for information about health in general, against $44.7 \%$ and $51.8 \%$ of the general Dutch population, respectively [15]. This might be related to fewer opportunities to travel and having more frequent contacts with health professionals, respectively.

About half of the participants with tetraplegia used one or more assistive devices to access their computer, mostly a typing aid or a trackball. The use of speech-recognition software, head or mouth controls, special mouse and special touch screen was low. This may be due to the few people with a level of SCI above C4 in our study. Nevertheless, such devices may make Internet use easier [23, 24]. May be the accessibility options of modern computers, such as standard voice activation and touch screens, have limited the need for special assistive devices for most people with a limited hand function.

We did not have a specific hypothesis on Internet use for SCI-related information, but the figures we found were surprisingly low in retrospect. The most often accessed

\begin{tabular}{llll}
\hline & $\begin{array}{l}\text { General Internet use } \\
(p \text {-value })\end{array}$ & $\begin{array}{l}\text { Health-related Internet } \\
\text { use }^{\mathrm{a}}(p \text {-value })\end{array}$ & $\begin{array}{l}\text { Online gaming (\% daily or } \\
\text { weekly })^{\mathrm{b}}(p \text {-value })\end{array}$ \\
\hline $\begin{array}{l}\text { Participation restrictions } \\
\text { Satisfaction with }\end{array}$ & $-0.02(0.806)$ & $-0.17(0.008)$ & $-0.08(0.442)$ \\
participation & $-0.04(0.490)$ & $-0.07(0.240)$ & $0.13(0.153)$ \\
Mental health & $-0.02(0.771)$ & $-0.04(0.483)$ & $-0.03(0.723)$ \\
$\begin{array}{l}\text { Life satisfaction } \\
\text { Quality of life }\end{array}$ & $-0.07(0.284)$ & $-0.11(0.074)$ & $-0.02(0.825)$ \\
\hline
\end{tabular}

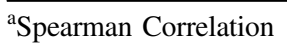

bomer's D 
SCI-related website was the site of the Dutch patients organization, but even this site was never visited by about half of our participants. Also, three-quarters indicated to never visit SCI-related websites in a foreign language. Other studies reported that about one-thirds up to $58 \%$ of people with SCI used the Internet for health information $[2,4,5]$. This indicates that many people with SCI do not benefit fully from all information on SCI and SCI-related health issues that is available to date. One possible explanation is that participants received their rehabilitation when the Internet did not exist. Alternatively, they may have been disappointed by the type and relevance of the information available. In an American study, participants rated the Internet as resource of health information high for speed and accessibility, but lower for accuracy and specificity [5]. A Spanish study showed that many websites with health or SCI-specific information lack readability or reliability [25]. Also, a lack of readiness to look for information about SCI and the overwhelming amount of information available may have limited this type of Internet use [26]. However, we may have underestimated the access to health information through the Internet because it is possible that participants get this information through other channels, such as specific Facebook groups or other social networks. Nevertheless, the possible underuse of health-related information on the Internet warrants further investigation.

Female gender, higher age, and lower level of education were associated with less general Internet use, and lower level of education was associated with less health-related Internet use. Differences due to age may partly be a temporary phenomenon, not only because the contemporary young will grow old, but also because contemporary elderly adopt Internet activities such as music and video, gaming and social media [7]. Differences due to level of education, however, reflect findings on inequalities in access to the Internet in the Dutch general population namely that lowereducated Internet users spent more time online in their spare time, but that those with higher social status use the Internet in more beneficial ways [7].

We found a weak significant association between more health-related Internet use and worse participation. One previous study found a similar result [8]. The interpretation of this finding is unclear. It could be the presence of secondary health conditions that both prompts health-related Internet use and limits participation, but it can also be a chance finding, this association was weak and the only significant association out of 15 associations tested. We could not confirm reports from earlier studies on a positive association between Internet use with lower depression [11], or better health-related quality of life (but not better mental health) [6], possibly because almost all of our participants used the Internet daily. We also could not confirm the previously reported significant correlation between online gaming and depression [12]. Probably the group of frequent gamers, with only $11.2 \%$ reporting daily use, was too small to show possible adverse effects of frequent gaming.

\section{Limitations}

Due to the inclusion criteria of the ALLRISC study, our study group is not representative for the Dutch SCI population. All participants were injured as young adults and at least 10 years before the study, were between 28 and 65 years of age at the time of the study, and all were wheelchair-user. Therefore we may have overestimated the Internet use of the average person with SCI in the Netherlands. On the other hand, our exclusion of people with a more recent onset of SCI may have led to an underestimation of this use.

Another limitation stems from the self-report nature of our data. The validity of this data is questionable due to memory effects. A study using of log-files to measure Internet use would provide more precise data.

Finally, data collection took mainly place in 2012-2013. Data on computer and Internet outdate quickly, for example the use of social media and in particular. For example, Internet use for health-related information in the general Dutch population increased from $51.8 \%$ in 2013 to $67.1 \%$ 2018 [15].

\section{Implications}

This study confirms the importance of the Internet for people with SCI. However, the low use of SCI-specific websites shows that information on the Internet does not reach everyone. This should be taken into consideration in the development of e-health applications.

Now that the Internet has become integral part of daily life, the most important source of health information and health interventions are more and more delivered through the Internet [5, 27, 28], computer access and education on obtaining health information and learn to get feeling for which information is reliable and which is not should be important rehabilitation goals. Also, integration of information developed by rehabilitation centers and information on the Internet, and e-health applications need further development.

\section{Conclusion}

Internet has become part of daily life of people with SCI in the Netherlands. However, only one association between Internet use and indicators of psychosocial functioning was 
found. Possible underuse of adaptive devices and of SCIspecific websites warrant further investigation.

\section{Data archiving}

The datasets analyzed during the current study are available from the corresponding author on reasonable request.

ALLRISC Group S. de Groot ${ }^{5,6}$, TWJ Janssen ${ }^{7}$, H. Bussmann ${ }^{8}$, C. Smit ${ }^{5}$, M. Sloots ${ }^{5}$, D. van Kuppevelt ${ }^{9}$, H. Rijken ${ }^{9}$, W. Faber ${ }^{10}$, L. Valent ${ }^{10}$ G. Snoek ${ }^{11}$ M. Schuitemaker ${ }^{11}$ F. Woldring ${ }^{2}$, H. Bongers ${ }^{12}$, S. Slangen ${ }^{12}$, M. Wynants ${ }^{12}$, T. Sluis ${ }^{13}$, R. Broeksteeg ${ }^{13}$, C. Dijkstra ${ }^{3}$, P. Luthart ${ }^{3}$

${ }^{6}$ Amsterdam Rehabilitation Research Centre, Reade, Amsterdam, The Netherlands; ${ }^{7}$ MOVE Research Institute Amsterdam, Faculty of Human Movement Sciences, VU University Amsterdam, Amsterdam, The Netherlands; ${ }^{8}$ Department of Rehabilitation Medicine and Physical Therapy, Erasmus MC University Medical Centre, Rotterdam, The Netherlands; ${ }^{9}$ Sint Maartenskliniek, Nijmegen, The Netherlands; ${ }^{10}$ Rehabilitation Center Heliomare, Wijk aan Zee, The Netherlands; ${ }^{11}$ Roessingh Rehabilitation Center, Enschede, The Netherlands; ${ }^{12}$ Adelante Zorggroep, Hoensbroek, The Netherlands; ${ }^{13}$ Rijndam Rehabilitation Center, Rotterdam, The Netherlands

Author contributions MWMP obtained funding for the study, analyzed the data and wrote the final manuscript. JMPL performed initial data analysis, wrote the first draft and provided feedback on the manuscript. MT and GJS contributed to the data collection and provided feedback on the manuscript. LHVvdW obtained funding for the study, coordinated the ALLRISC research program and provided feedback on the manuscript. JJEA wrote the study protocol, coordinated the data collection and provided feedback on the manuscript.

Funding ALLRISC is sponsored by "Fonds NutsOHRA" under the responsibility of the Netherlands Organization for Health Research and Development (www.ZonMW.nl), Project number 89000006.

\section{Compliance with ethical standards}

Conflict of interest The authors declare that they have no conflict of interest.

Ethical approval The research protocol was approved by the Medical Ethics Committee of the University Medical Center Utrecht (protocol number 11-156/E; NL36394.041.11, version 4). We certify that all applicable institutional and governmental regulations concerning the ethical use of human volunteers were followed during the course of this research.

Publisher's note: Springer Nature remains neutral with regard to jurisdictional claims in published maps and institutional affiliations.

\section{References}

1. Cheatham LP. Effects of Internet use on well-being among adults with physical disabilities. Disabil Rehabil Assist Technol. 2012;7:181-8.

2. Hogan TP, Hill JN, Locatelli SM, Weaver FM, Thomas FP, Nazi $\mathrm{KM}$, et al. Health Information seeking and technology use among veterans with spinal cord injuries and disorders. PM R. 2016;8:123-30.

3. O'Riley AA, Rose J, Dalal B. Online support for individuals with spinal cord injuries: an ethnographic investigation. J Spinal Cord Med. 2014;37:179-85.

4. Matter B, Feinberg M, Schomer K, Harniss M, Brown P, Johnson K. Information needs of people with spinal cord injuries. J Spinal Cord Med. 2009;32:545-54.

5. Burkell JA, Wolfe DL, Potter PJ, Jutai JW. Information needs and information sources of individuals living with spinal cord injury. Health Info Libr J. 2006;23:257-65.

6. Celik B, Ones K, Celik EC, Bugdayci DS, Paker N, Avci C, et al. The effects of using the Internet on the health-related quality of life in people with spinal cord injury: a controlled study. Spinal Cord. 2014;52:388-91.

7. AJAM VanDeursen, van, JAGM Dijk. The digital divide shifts to differences in usage. New Media Soc. 2014;16:507-26.

8. Drainoni ML, Houlihan B, Williams S, Vedrani M, Esch D, LeeHood E, et al. Patterns of Internet use by persons with spinal cord injuries and relationship to health-related quality of life. Arch Phys Med Rehabil. 2004;85:1872-9.

9. Goodman N, Jette AM, Houliban B, Williams S. Computer and Internet use by persons after spinal cord injury. Arch Phys Med Rehabil. 2008;89:1492-8.

10. Houlihan BV, Drainoni ML, Warner G, Nesathurai S, Wierbicky $\mathrm{J}$, Williams S. The impact of Internet access for people with spinal cord injuries: a descriptive analysis of a pilot study. Disabil Rehabil. 2002;25:422-31.

11. Tsai IH, Graves DE, Lai CH, Hwang LY, Pompeii LA. Association of internet use and depression among the spinal cord injury population. Arch Phys Med Rehabil. 2014;95:236-43.

12. Miller SM. The effect of frequency and type of Internet use on perceived social support and sense of well-being in individuals with spinal cord injury. Rehabil Couns Bull. 2008;51:148-58.

13. Van der Woude LH, de Groot S, Postema K, Bussmann JB, Janssen TW, ALLRISC. et al. Active LifestyLe Rehabilitation interventions in aging spinal cord injury (ALLRISC): a multicentre research program. Disabil Rehabil. 2013;35:1097-103.

14. Adriaansen JJE, van Asbeck FWA, Lindeman E, van der Woude LHV, de Groot S, Post MWM. Secondary health conditions in persons with a spinal cord injury for at least 10 years: design of a comprehensive long-term cross-sectional study. Disabil Rehabil. 2013;35:1104-10.

15. Central Bureau of Statistics. Statline. Retrieved 10 December 2018, from https://opendata.cbs.nl/\#/CBS/nl/dataset/83429NED/ table?ts $=1544779223982$

16. Kirshblum SC, Burns SP, Biering-Sorensen F, DonovanW, Graves DE, Jha A, et al. International standards for neurological classification of spinal cord injury (revised 2011). J Spinal Cord Med. 2011;34:535-46.

17. Ware JE, Sherbourne CD. The MOS 36-itme short-form health survey (SF-36). I. Conceptual framework and item selection. Med Care. 1992;30:473-83.

18. Van Leeuwen CMC, van der Woude LHV, Post MWM. Validity of the mental health subscale of the SF-36 in persons with spinal cord injury. Spinal Cord. 2012;50:707-10.

19. The WHOQOL Group. The World Health Organization Quality of Life Assessment (WHOQOL): development and general psychometric properties. Soc Sci Med. 1998;46:1569-85.

20. Geyh S, Fellinghauer BAG, Kirchberger I, Post MWM. Crosscultural validity of four quality of life scales in persons with spinal cord injury. Health Qual Life Outcomes. 2010;8:94.

21. Post MW, van der Zee CH, Hennink J, Schafrat CG, Visser-Meily JM, van Berlekom SB. Validity of the Utrecht scale for evaluation of rehabilitation-participation. Disabil Rehabil. 2012; $34: 478-85$. 
22. Van der Zee CH, Post MWM, Brinkhof MW, Wagenaar RC. Comparison of the utrecht scale for evaluation of rehabilitationparticipation with the ICF measure of participation and activities screener and the who disability assessment schedule II in persons with spinal cord injury. Arch Phys Med Rehabil. 2014;95:87-93

23. Caltenco HA, Breidegard B, Jönsson B, Andreasen Struijk LNS. Understanding computer users with tetraplegia: Survey of assistive technology users. Int J Hum Comput Interact 2012; 28:258-68.

24. Pouplin S, Roche N, Vaugier I, Cabanilles S, Hugeron C, Bensmail D. Text input speed in persons with cervical spinal cord injury. Spinal Cord. 2016;54:158-62.
25. Bea-Muñoz M, Medina-Sánchez M, Flórez-García MT. Quality of websites with patient information about spinal cord injury in Spanish. Spinal Cord. 2016;54:540-5.

26. Manns PJ, May LA. Perceptions of issues associated with the maintenance and improvement of long-term health in people with SCI. Spinal Cord. 2007;45:411-9.

27. Coulter EH, McLean AN, Hasler JP, Allan DB, McFadyen A, Paul L. The effectiveness and satisfaction of web-based physiotherapy in people with spinal cord injury: a pilot randomised controlled trial. Spinal Cord. 2017;55:383-9.

28. Verwer JH, van Leeuwen CM, Bolier L, Post MW. Feasibility of an online well-being intervention for people with spinal cord injury: a pilot study. Spinal Cord. 2016;54:473-7. 